\title{
LA CIUDAD TERRITORIO LOGÍSTICO: PLATAFORMA LOGÍSTICA DE VEREDA DE PALOMARES EN VALLADOLID
}

\author{
Basilio CALDERÓN CALDERÓN - Luis J. PASTOR ANTOLÍN \\ Departamento de Geografía.Universidad de Valladolid
}

Las últimas decisiones estratégicas en materia de infraestructura de transportes que afectan a la ciudad de Valladolid, especialmente las relacionadas con la Alta Velocidad, son el preludio no sólo de un incremento de actividad económica, sino también de un cambio en su estructura, previsiblemente en favor del transporte y sobre todo la logística ya que, por su especial capacidad de generar valor añadido, alimentará un crecimiento sostenido del conjunto del sistema y permitirá a numerosas empresas locales y regionales concentrarse en su negocio -“core business"- y externalizar o subcontratar -“outsourcing"- las operaciones no relacionadas con él.

Obviamente, el funcionamiento del negocio logístico, especialmente si al negocio clásico - la gestión de inventarios, conformación de pedidos y gestión de entregas- se añaden actividades de valor añadido -redocumentación técnica del producto, etiquetado, facturación, servicio postventa, gestión de flujos de retorno etc...-, precisa de un tipo de infraestructuras de soporte -suelo- y de relación -transporte- ciertamente excepcionales. Conocidas las primeras, ya que la localización de la estación de mercancías en el sector 49 del PGOU de Valladolid Vereda de Palomares-, será el motor de la futura plataforma logística, es preciso hacer hincapié y valorar el estado y capacidad de las segundas -las infraestructuras de transporte-, así como la estructura de los principales centros generadores de carga - y por lo tanto de tráfico- en la ciudad de Valladolid. Pero, con anterioridad, será preciso destacar el papel de la actividad logística y de los nuevos centros especializados en ella -plataformas o zonas de actividades logísti-

\footnotetext{
${ }^{1}$ Este artículo ha sido elaborado en el marco del proyecto Análisis y valoración de los nuevos factores de competitividad urbana: un enfoque integral y comparado de las políticas públicas de gestión de la ciudad, perteneciente al Programa Nacional de Promoción del Conocimiento (Área de Ciencias Sociales) del Ministerio de Educación. Referencia: BS02002-02013. Ha colaborado también la CVE de Valladolid.
} 
cas- en el horizonte económico de aquellos territorios que, por su especial posición estratégica, están llamados a ser su soporte natural.

\section{LA LOGÍSTICA. ENTRE LA GESTIÓN DE LA ACTIVIDAD ECONÓMICA Y LA ORDENACIÓN DEL TERRITORIO.}

Es sabido que prácticamente todos los sectores de la economía a los que sirve la industria del transporte están aumentando la externalización de los ciclos de su actividad no relacionados con áreas estratégicas o competencias básicas de su negocio. La subcontratación u "outsourcing" logístico es la delegación de toda o parte de la actividad logística de una compañía en otra empresa especializada que aporta su experiencia y habilidad para realizar una administración eficiente de la actividad delegada, permitiendo transformar costes fijos en variables y liberar recursos para otras funciones dentro de la empresa.

Tradicionalmente, las actividades asociadas al concepto de logística, han sido el reparto de mercancías, el transporte de larga distancia y el almacenaje, si bien es cierto que a estas actividades se han ido añadiendo y generalizando otras actividades no menos relevantes: la preparación de pedidos, la gestión de existencias y suministros y el "merchandising" -ver cuadro $n^{\circ} 1-$.

Cuadro 1. Una aproximación a las actividades relacionadas con la logística.

Operaciones físicas Transporte (cargas completas, grupaje): Larga distancia (monomodal, multimodal), Almacenaje: Manipulación de recepción (descarga), Fraccionamiento, Clasificación, Preparación de pedidos, Expedición (carga) Complementarias: Etiquetado, Embalaje, Merchandising, Facturación, Cobros, Montaje....

\begin{tabular}{ll}
\hline Operaciones de gestión & $\begin{array}{l}\text {-Organización de rutas, Gestiones aduaneras (interna- } \\
\text { cional), Controles de cantidad y calidad de productos, } \\
\text { Gestión de stocks, Gestión de caducidades de productos }\end{array}$ \\
\hline $\begin{array}{l}\text { Tratamiento de la informa- } \\
\text { ción }\end{array}$ & $\begin{array}{l}\text {-Documentación generada por remitentes, Documenta- } \\
\text { ción generada por destinatarios, Información utilizada } \\
\text { por el operador logístico, Sistemas de transmisión de la } \\
\text { información etc... }\end{array}$ \\
\hline
\end{tabular}

Pero, en la actualidad, el concepto de logística no sólo incluye aspectos directamente relacionados con la gestión de la empresa con relación a sus proveedo- 
res y clientes (logística externa) y sus procesos logísticos relacionados con la producción (logística interna), sino también aquellas decisiones que afectan al ámbito de las políticas públicas locales, como nacionales y hasta transnacionales, o las que afectan a las infraestructuras de transporte (puertos, aeropuertos, ferrocarril, etc.), o a la definición de zonas de actividad logísticas o de transporte intermodal en los grandes corredores europeos ${ }^{2}$.

Gracias a su carácter integrador, el mercado mundial de la logística mueve en torno a 3 billones de euros, cifra que representa el 11,7\% del PIB mundial. Esa participación del mercado logístico en el conjunto de la actividad económica es similar en las principales áreas desarrolladas -12\% en EE.UU., 11,7\% en Europa, 11,5\% en España-, según un informe sectorial realizado por la Federación de Cajas de Ahorros Vasco-Navarras ${ }^{3}$. El estudio considera que la subcontratación de servicios logísticos alcanzará los 44.000 millones de euros, lo que supone un incremento del $40 \%$ respecto a 1996. Así, las actividades logísticas subcontratadas por las empresas a los operadores logísticos representaban en 2002 algo más del $28 \%$ del total del mercado logístico, frente al $24 \%$ observado en 1996. Por países, el principal mercado logístico es el alemán (26,8\%), seguido por el francés $(19,9 \%)$ y el británico $(18,3 \%)$. En este contexto, el mercado español se presenta como uno de los más dinámicos de la UE y se estima que el gasto en logística alcanzará los 8.621 millones de euros en 2002, lo que supone un crecimiento del 25\% respecto a la cifra registrada en 1996 (6.896 millones de euros $)^{4}$.

Cuadro 2. Operadores logísticos en España.

\begin{tabular}{lrrrr}
\hline Concepto & $\mathbf{1 9 9 8}$ & $\mathbf{1 9 9 9}$ & $\mathbf{2 0 0 0}$ & $\mathbf{2 0 0 1}$ \\
\hline $\mathrm{N}^{\mathbf{o}}$ de Empresas & 115 & 130 & 160 & 175 \\
$\mathrm{~N}^{\mathbf{o}}$ de Empleados & 13.000 & 15.000 & 18.500 & 20.000 \\
Media de Empleados por Empresa & 113 & - & 116 & 114 \\
Mercado* $_{\text {Crecimiento del Mercado }(\%)}$ & 200.000 & 244.000 & 260.000 & 1.900 \\
Cuota de Mercado (5 as $^{\text {as }}$ Empr. (\%) & 19,0 & 22,0 & 20,8 & 38,4 \\
\hline
\end{tabular}

*Cifras expresadas en millones de ptas. excepto 2001 (millones de $€$ )

Fuente: http://www.guiame.net/flash/logistica.html

\footnotetext{
${ }^{2}$ http://magno.uab.es

${ }^{3}$ http://www.fcavn.es
}

Polígonos. Revista de Geografia, 11-12 (2001-2002); pp.11-44. 
Estas expectativas de crecimiento están en parte basadas en las tendencias previstas en la llamada gestión de la cadena de suministro. Ya se ha generalizado un proceso de concentración de instalaciones a escala de cada empresa y a escala de conjunto; se está reforzando también el transporte intermodal, que redunda en particular en una mejora de la eficiencia del transporte ferroviario; está creciendo el papel de las nuevas tecnologías de la información y comunicación para mejorar tanto la gestión interna de la empresa, como las relaciones entre empresas (Business to Business, B2B) y la relación entre las empresas y sus clientes (Business to Consumer, B2C); y es también muy destacable el papel de la llamada "cadena de suministro verde" vinculada a una mayor conciencia medioambiental, así como la llamada "logística inversa", toda vez que una legislación cada vez más severa presiona para que los fabricantes se responsabilicen de los productos al final de su vida útil.

A la vista de estas tendencias queda fuera de toda duda que la logística presenta en España grandes expectativas de desarrollo, debido tanto su relativa inmadurez, como a su situación geográfica estratégica en el contexto internacional y a que goza de unas infraestructuras logísticas (centros de transporte, puertos, ferrocarril y aeropuertos) relativamente desarrolladas y con unas expectativas de mejora garantizadas por los planes plurianuales de inversión del Ministerio de Fomento 5 .

$Y$ es que, la existencia de unas adecuadas infraestructuras para el establecimiento de operadores logísticos constituye un elemento esencial en la toma de decisiones de localización industrial por parte de las empresas, ya que permiten no sólo el intercambio de mercancías entre los diferentes modos de transporte y el acceso a las principales redes de tráfico, sino una importante reducción de los costes de fricción en un entrono de operatividad, innovación y desarrollo. Baste señalar que, según la Asociación de Centros de Transporte de España (ACTE), en la actualidad, el valor medio en Europa de los costes logísticos se estima en un $14 \%$ del precio de venta, y entre el $30 \%$ y el $60 \%$ de los costes de produc-

${ }^{4}$ http://www.estrategia.net

${ }^{5}$ El Libro Blanco de Transporte -2001-, que tiene una vigencia de nueve años, contempla 60 medidas orientadas a la consecución, entre otros de objetivos tales como aumentar el peso del ferrocarril, mejorar la calidad del transporte por carretera, promover el modo marítimo, potenciar la intermodalidad, crear una red ferroviaria exclusiva para mercancías. La Logística en España. Estudio de Situación 2001. Consorcio de la Zona Franca de Barcelona y centro español de la Logística. 
ción. La tendencia de los últimos años ha demostrado que la existencia y el desarrollo de plataformas logísticas y centros de transporte contribuyen precisamente a reducir esos costes implícitos en la cadena logística.

Por ello, y de forma progresiva, cada vez es mayor el número de empresas de los subsectores de la logística (agencias de carga completa y fraccionada, almacenaje y distribución, aduanas, grupaje, servicios generales, bancos, seguros, centros de formación, etc.) que deciden instalarse en una plataforma logística o simplemente en un centro de transportes, ya que en ellos, como se señala más adelante, se dispone de instalaciones físicas diseñadas específicamente para las actividades logísticas. ${ }^{6}$

\section{EL ESPACIO DE LA LOGÍSTICA: LAS INFRAESTRUCTURAS NODALES Y PLATAFORMAS LOGÍSTICAS.}

En correspondencia con las transformaciones verificadas en la actividad y el ciclo logísticos, desde principios del decenio de los ochenta se ha producido la aparición y la progresiva difusión y consolidación de un tipo especializado de infraestructuras terminales o nodales, que, bajo denominaciones y contenidos funcionales notablemente diferenciados (plataformas logísticas, zonas de actividades logísticas, centros de distribución intermodales y más recientemente, aunque con connotaciones funcionales muy precisas, puertos secos), pueden tipificarse genéricamente como puntos o áreas de ruptura de las cadenas de transporte, en los que se desarrollan actividades y funciones técnicas de naturaleza logística, que con frecuencia incorporan valor añadido a las mercancías. Se trata, pues, de una emergente modalidad de infraestructuras que, estrechamente articuladas con las redes plurimodales de espacios de relación de gran capacidad, constituyen el reflejo espacial de la vigorosa progresión de la actividad logística y de las fuertes mutaciones que la misma está induciendo en el sector del transporte.

\subsection{Rasgos y clasificación funcional de los centros logísticos.}

Una consideración más explícita revela que las infraestructuras logísticas o nodales, consideradas en su conjunto, despliegan total o parcialmente tres grandes tipos de funciones: En primer lugar, actúan como punto de ruptura de carga $y$, en el contexto de una tendencia claramente dominante, como centro de co-

\footnotetext{
${ }^{6}$ http://www.puntolog.com
} 
nexión y coordinación intermodal, favoreciendo, por consiguiente, la organización de los servicios de transporte combinado. En segundo lugar, las infraestructuras nodales operan como centro de recepción de mercancías de procedencias diversas y, en calidad de rasgo funcional identificador, como puntos de clasificación de las mismas y de redistribución a los clientes destinatarios, mediante las ventajas proporcionadas por el almacenamiento intermedio de calidad y de la organización de las cadenas de transporte. Por último, la realización en mayor o menor medida de una amplia y diversificada gama de funciones complementarias, entre las que cabe destacar las actividades asociadas al comercio internacional (gestiones aduaneras, control sanitario), gestión de stocks, operaciones de tratamiento adicional de la carga externalizadas cada vez con más frecuencia por la empresas industriales y comerciales (envasado, etiquetado, empaquetamiento en palets...etc....), así como servicios de carácter más básico destinados al estacionamiento y mantenimiento del material rodante (aparcamiento vigilado, áreas de autoservicio de combustible y lubricantes, fosos y equipos para servicios de lavado de los vehículos...), servicios a las empresas de transporte (asesoramiento profesional y empresarial, asistencia a la gestión e innovación de la empresa, gestión de búsqueda de cargas y cálculo de precios en el itinerario óptimo, servicio de gestión de sanciones de transporte y tráfico), servicios a los conductores (instalaciones para el aseo personal, sala de espera y descanso, asesoramiento en sanciones de tráfico y, en los centros que disponen de edificios suficientes en superficie, restaurante, hostal u hotel y otros servicios para el conductor desplazado), servicios a cargadores (información sobre vehículos disponibles en el recinto o en otras áreas)...etc..

Como es obvio, los centros logísticos deben acomodarse a unos patrones de localización que permitan una excelente articulación con los nodos y redes de infraestructuras viarias y ferroviarias de gran capacidad y, en su caso, con los puertos de significativa proyección, así como la proximidad a mercados y proveedores, esto es, a amplias áreas de tejido productivo demandantes de actividades logísticas y de transporte. En cualquier caso, la mencionada diversificación funcional de los centros logísticos nos pone sobre la pista de la variada tipología de infraestructuras logísticas que se hallan operativas en la actualidad, aspecto sobre cuya conceptualización y denominación no existe consenso alguno. De hecho, la ambigüedad y la ambivalencia terminológicas introducen la nota dominante al abordar el estudio de los espacios destinados al desarrollo de las actividades de carácter logístico. En una primera aproximación y con una 
orientación meramente indicativa, se puede esbozar una sucinta clasificación de infraestructuras logísticas o nodales, atendiendo ante todo al nivel funcional de los servicios, al grado de diversificación de las actividades y a la escala del área de influencia de las mismas. De este modo, es posible identificar al menos cuatro grandes modalidades de infraestructuras logísticas:

- los centros de transporte de mercancías, que, orientados de forma progresiva hacia la intermodalidad, aunque asociados con frecuencia al transporte por carretera, incorporan tan sólo los servicios más elementales a conductores, vehículos y empresas de transporte. De hecho, operan habitualmente como infraestructuras complementarias para el transporte de mercancías por carretera y muestran el carácter propio de centros de servicios al transporte, perfilándose, asimismo, como una iniciativa destinada a racionalizar la localización en el espacio urbano y metropolitano de las empresas, actividades y vehículos pesados vinculados al transporte de mercancías.

- los centros integrados de mercancías (CIM), que representan un nivel funcional más evolucionado, al identificarse con centros de actividades logísticas propiamente dichos, frecuentemente de carácter plurimodal, con instalaciones dotadas de almacenes, naves de transporte y distribución. Igualmente cuentan con zonas aduaneras, servicios para conductores, vehículos y empresas de transporte y con un centro de comunicaciones, que proporciona el soporte tecnológico al desarrollo de las diversas actividades del ciclo logístico. Los centros integrados de mercancías pueden operar como plataformas de proximidad o de distribución urbana (city-logistics), si bien su área de influencia y operaciones puede alcanzar la escala subregional o regional.

- una modalidad específica de infraestructura logística es la que se conoce bajo la denominación de puerto seco, centro de distribución intermodal al servicio de uno o varios puertos, constituido por un terminal de transporte combinado ferroportuario, especializado en el tratamiento logístico del tráfico marítimo, en el que se realizan una serie de operaciones que aumentan el valor añadido de las mercancías (JIMÉNEZ DE CISNEROS, 1997). Por consiguiente, un puerto seco desarrolla habitualmente las siguientes funciones: recepción y expedición de trenes -bajo la modalidad de trenes puros de contenedores, en España TECO-, carga, descarga y almacenamiento de contenedores y las operaciones logísticas comple- 
mentarias ligadas a las anteriores. A fin de poder abordar adecuadamente la realización de estas operaciones, el puerto seco está integrado por una infraestructura ferroviaria -eje o ramal- que canalice las mercancías desde o hacia los puertos, un terminal de contenedores y los equipos y medios personales que complementen dichas operaciones. En definitiva, se trata de una infraestructura que prolonga hacia el interior las instalaciones y actividades logísticas características de un puerto, a través de concurso del transporte combinado.

- la plataforma logística representa, sin duda alguna, el más alto nivel funcional de las infraestructuras nodales, definiendo un espacio delimitado en cuyo interior distintos operadores realizan todas o gran parte de las actividades relacionadas con el transporte, la logística y la distribución de mercancías, tanto para el tráfico nacional como el de alcance internacional. Las plataformas logísticas deben estar dotadas de terminales de intercambio intermodal, marítimo-ferroviario-carretera en el supuesto óptimo, al tiempo que resulta altamente operativa su adecuada articulación con algún terminal o centro de carga aérea.

Una de las denominaciones que ha adquirido mayor difusión es la de Zona de Actividades Logísticas (ZAL), aunque la determinación de su contenido funcional presenta un alto grado de indefinición. En efecto, determinados autores y estudios técnicos se decantan por concebir la ZAL como el territorio que constituye el área de influencia de una plataforma logística de elevado nivel funcional, mientras que en otros casos la Zona de Actividades Logísticas aparece tipificada como el conjunto de centros e infraestructuras de un área metropolitana o espacio subregional destinados a la realización de las actividades que integran el ciclo logístico, esto es, transporte, almacenaje, manipulación y distribución. No obstante, y con suma frecuencia, la denominación de Zona de Actividades Logísticas aparece identificada con una plataforma logística de amplia oferta de servicios y actividades y gran escala de su correspondiente área de influencia.

La promoción y gestión de las infraestructuras logísticas se perfila como uno de los ámbitos más ejemplificadores de la colaboración entre Administraciones y de cooperación y asociación del sector público y el privado. La iniciativa de la promoción de los centros logísticos suele recaer habitualmente en la Administración Municipal (Ayuntamiento o, en menor medida, Mancomunidad de Municipios o Diputación Provincial), que con frecuencia aporta el suelo y tiene una destacada participación en la financiación. La intervención de la Comuni- 
dad Autónoma se materializa, por un lado, a través de la aprobación de un reglamento marco o de la normativa general de centros logísticos, a fin de facilitar la homologación técnica de los mismos para su integración en redes, y, por otro, en la cofinanciación, canalizando además de recursos propios los suministrados por los Fondos Estructurales comunitarios. Por su parte, y como se señalará más adelante para las plataformas logísticas, la colaboración de la Administración General del Estado puede efectuarse mediante la cofinanciación en régimen de concertación, propiciando la participación del Ministerio de Fomento y de entidades dependientes del mismo como RENFE y el GIF, así como, en su caso, AENA y las diversas Autoridades Portuarias. Finalmente, la redacción del proyecto, la construcción de las instalaciones y, ante todo, la gestión de la infraestructura logística puede realizarla una empresa pública o mixta, en la que participen todas o varias de las Administraciones y entidades Públicas mencionadas y los operadores logísticos privados y empresas de transporte interesadas.

\subsection{El singular nivel funcional de las plataformas logísticas}

En virtud de su especial significación funcional y territorial, es conveniente efectuar una consideración más específica acerca de las plataformas logísticas. Asumiendo y desarrollando la noción anteriormente apuntada, y haciéndonos parcialmente eco de la definición recogida en un estudio especializado del Ministerio de Fomento, la plataforma logística es un espacio delimitado en el que se desarrollan, por parte de diversos operadores, todas o gran parte de las actividades relativas al transporte, la logística y la distribución de mercancías, tanto para los flujos de tráfico nacional como los de carácter internacional (MINISTERIO DE FOMENTO, 1999). La plataforma debe estar dotada, asimismo, de los equipos necesarios para el buen funcionamiento de estas actividades, así como de cualquier otro tipo de instalaciones que permitan intercalar procesos que aumenten el valor añadido de las mercancías. Por lo demás, la plataforma debe proceder a la prestación completa de los servicios especializados y los de carácter complementario destinados a los conductores, vehículos y empresas de transporte. Desde el punto de vista operativo y de gestión, es importante subrayar el destacado protagonismo de los operadores logísticos privados, que pueden utilizar en régimen de propiedad o de arrendamiento los edificios, equipos e instalaciones (almacenes, naves de distribución, oficinas, eventualmente muelles...etc.) construidos o establecidos en la plataforma. En cualquier caso, ésta debe regularse en el marco de un régimen de libre concurrencia para todas las 
empresas interesadas en las mencionadas actividades de transporte y logística y la gestión de la plataforma en su conjunto debe corresponder a una entidad única, de carácter público o privado.

Se trata, pues, de las infraestructuras nodales que, a juicio de Roger Brunet, pueden ser tipificadas como plataformas logísticas con integración de servicios en sentido estricto (BRUNET, 1993). Proyectan su área de operaciones a escala suprarregional, nacional e, incluso, sobre amplios sectores de las redes de la Unión Europea, estando acondicionadas para efectuar con eficacia la clasificación y la redistribución de cargas con un alcance al menos de 600 kms. Junto a los anteriormente señalados, algunos de los rasgos funcionales y tecnológicos que singularizan en el momento presente a las plataformas logísticas se hacen visibles en su especialización en la gestión eficaz de stocks de rotación rápida y en el uso intensivo del soporte informático y de las telecomunicaciones para el desarrollo, entre otros, de los servicios de información y toma de decisiones relativas a flujos y bolsas de mercancías, la evolución de los mercados, reglamentaciones jurídicas y financieras..., así como para la gestión informática de entradas y salidas de vehículos y cargas, transbordos, estado y evolución de los stocks...etc...

En definitiva, teniendo presente que en la actualidad un vehículo raramente puede asegurar todo el ciclo del transporte desde el lugar de producción al de consumo final y que, por tanto, las rupturas de carga son inevitables, las plataformas logísticas permiten atenuar e, incluso, anular el coste y la inversión en tiempo de estas rupturas, al incorporar en las mismas operaciones de valorización de la mercancía. Por lo demás, las plataformas logísticas se localizan prioritariamente en las proximidades de áreas metropolitanas y de ciudades que posean una situación estratégica en la red plurimodal de infraestructuras de transporte, dispongan de un extenso tejido empresarial con amplio volumen de transacciones exportadoras e importadoras y que, asimismo, muestren un elevado rango en la dotación de servicios.

En correspondencia con su perfil funcional, la estructura interna de las plataformas logísticas permite la identificación y delimitación de, al menos, tres áreas funcionales, entendiendo por tales los espacios o ámbitos con cierta homogeneidad de actividades y función unitaria en el seno de la plataforma. Es posible individualizar, en primer lugar, el área de servicios, que proporciona acogida a los servicios centrales, a los servicios destinados a empresas de transporte, conductores y vehículos -integrando, por consiguiente, las instalaciones 
de suministro de carburantes, talleres de reparación y mantenimiento de vehículos y equipos, las grandes superficies dedicadas al aparcamiento de vehículos pesados, edificios para la atención de tripulantes, zonas de descanso...etc.-, así como a los servicios aduaneros, gestionados por la Agencia Tributaria.

El segundo de los elementos funcionales constitutivos de las plataformas aparece identificado con las áreas logísticas propiamente dichas, de las que forman parte las áreas de transferencia, primordialmente orientadas a la carga y descarga de mercancías, las áreas de almacenamiento y distribución -también conocidas bajo la denominación de distriparks- y, asimismo, las áreas de logística y distribución urbana -las ya mencionadas city-logistics-, que pueden estar integradas en una plataforma de alto nivel funcional u organizarse como una infraestructura logística de localización y dinámica diferenciadas. El área logística está habitualmente estructurada como una zona de naves de almacenamiento y distribución, de dimensiones variables, donde se ubican los operadores logísticos privados y a las que se accede a través de los correspondientes muelles. Es importante señalar, no obstante, la existencia en plataformas de gran escala de áreas logísticas especializadas o monofuncionales, entre las que cabe destacar las denominadas plataformas agroalimentarias, plataformas de logística de graneles, áreas de logística de mercancías peligrosas, de automóviles...etc.. Es previsible que a medio y largo plazo protagonicen una dinámica emergente las unidades ligadas a la que comienza a conocerse como logística inversa, destinadas a la gestión de residuos (productos, componentes, envases y embalajes usados) hasta su reciclaje y reutilización.

Por último, la tercera de las áreas funcionales de las plataformas está configurada por los espacios destinados a la conexión intermodal, pudiendo revestir los caracteres diferenciados de áreas intermodales ferrocarril-carretera, áreas intermodales de transporte aéreo-carretera o, igualmente, áreas intermodales de transporte marítimo o fluvial-modo terrestre. En estos espacios de enlace intermodal están localizados los terminales y playas de contenedores. Por lo demás, la estructura de las plataformas se completa con el trazado de viales, que proporcionan acceso al centro logístico, y que conjuntamente con los espacios libres públicos permiten la articulación interna del mismo. Y es que la estructura espacial de las plataformas se torna cada vez más relevante, ya que las empresas usuarias de las actividades logísticas y de transporte valoran por encima del precio de las mismas un diseño de las plataformas que favorezca su accesibilidad y funcionalidad. 
Conviene poner énfasis en el apreciable protagonismo que despliegan en las plataformas los operadores logísticos privados, que, en correspondencia con la especialización de cada empresa o grupo, ofertan y desarrollan todas las actividades del ciclo logístico, en concreto: el transporte, tanto de larga distancia como la distribución capilar, a través de vehículos propios o de subcontratados a empresas de transporte; la decisiva actividad de almacenaje -que comprende las operaciones de descarga, fraccionamiento, clasificación y ubicación de la mercancía en el almacén, preparación de pedidos y expedición de la carga-; las actividades complementarias, que incorporan valor añadido al tratamiento de las mercancías (etiquetado, embalaje, algunas operaciones de montaje, así como eventualmente facturación y cobros); las operaciones de gestión, externalizadas con frecuencia creciente por empresas industriales y comerciales (organización de itinerarios óptimos, gestión de stocks, controles de calidad y cantidad de los productos, gestión de caducidades de los mismos...) y, por supuesto, el tratamiento de la información, de incidencia determinante en el funcionamiento eficiente de todas las actividades logísticas, haciéndose extensivo a la gestión de la documentación generada por remitentes y destinatarios y a la puesta a punto de los sistemas de transmisión de la información.

Como aparece propuesto en el Plan Estratégico de Transporte de Mercancías por Carretera (PETRA), los operadores logísticos deben adaptarse a las nuevas tecnologías a fin de integrar las diferentes etapas del flujo de mercancías, esto es, la cadena de transporte, desde la recogida-aprovisionamiento hasta la entrega-distribución, pasando por el almacenamiento. Asimismo, los operadores encuentran en internet el medio idóneo para proceder a la integración de las diferentes etapas del flujo de información, es decir, los sistemas de información que enlazan al cliente-cargador, a los transportistas subcontratados y al propio operador logístico. Junto al soporte informático y la amplia extensión de los sistemas de información, uno de los medios tecnológicos que permiten esta integración del flujo de mercancías y el de información estriba en la utilización de tarjetas inteligentes tipo chip (TAG). El uso conjunto de las nuevas tecnologías permite a los operadores logísticos abordar, por un lado, una eficaz gestión de almacenes (los denominados almacenes inteligentes), ya que, mediante el sistema de identificación y captura de datos basado en Tags, es posible controlar en todo momento el stock de cada uno de los almacenes, y, por otro, una adecuada gestión de mercancías, puesto que la lectura de los Tags hace posible conocer la situación de la mercancía en almacenes o vehículos, mientras que el GPS per- 
mite localizar la carga cuando se encuentra embarcada. De igual modo, los diferentes optimizadores delinean la ruta óptima con actualizaciones on line, conforme la red capilar recibe peticiones de recogida. Por lo demás, los nuevos medios tecnológicos también posibilitan que los operadores logísticos aborden con garantía la gestión del transporte, de la flota y los recursos humanos, así como la realización de operaciones de estudio de mercado.

Adoptando una visión de conjunto en el tratamiento de los centros logísticos, se hace preciso elevar los umbrales de coordinación, complementariedad y homogeneización técnica y funcional de la red de plataformas logísticas a escala nacional, sobre todo en el momento presente en el que se asiste al establecimiento de una segunda generación de grandes infraestructuras logísticas, que, asentadas en la intermodalidad, tiene algunas de sus iniciativas más emblemáticas en las plataformas de Zaragoza (PLAZA), Rivabellosa en Álava o Salvatierra en Vigo, además de Zonas de Actividades Logísticas portuarias y nuevos centros de carga aérea. Es necesario, pues, el apoyo activo de la Administración Central del Estado en la creación de una red nacional concertada de plataformas logísticas de primer orden, estrechamente articulada con las Redes Transeuropeas de Transporte y, singularmente, con la de Transporte Combinado.

Como ya se ha apuntado, no obstante, en la planificación, promoción, financiación y gestión de las plataformas logísticas participan varias Administraciones Públicas y agentes privados. De ahí que previamente resulte imprescindible elevar la intensidad y el rango de la intervención de las Comunidades Autónomas en la configuración de la red regional de plataformas logísticas, complementando los ámbitos habituales de participación de los Ayuntamientos y las empresas del sector logístico y del transporte.

En efecto, a pesar de que en el planeamiento urbanístico a escala municipal los centros logísticos reciban el tratamiento de una dotación integrante del Sistema General de Servicios Urbanos o del Sistema General de Viales e Infraestructuras de Transporte, las Comunidades Autónomas deben proceder a una planificación estratégica de la red regional de plataformas logísticas, que, debidamente coordinada a escala nacional, pueda servir como base para una planificación concertada con el Estado. En este contexto, pues, la Administración Estatal puede diseñar un programa de ayudas para la ejecución de proyectos de plataformas logísticas de interés para el sistema nacional de transporte. 


\section{LA POSICIÓN ESTRATÉGICA DE VALLADOLID COMO NÚCLEO ARTICULADOR DE LA RED DE TRANSPORTE DEL NOROESTE PENINSULAR (Figs. 1 y 2 ).}

\subsection{Valladolid como núcleo de privilegiada accesibilidad en la red viaria del cuadrante noroccidental ibérico}

Valladolid presenta un excelente nivel de accesibilidad y una posición estratégica en el marco de la red de infraestructuras de transporte y, en concreto, de la trama viaria que articula el cuadrante noroccidental de la Península Ibérica. En efecto, la capital vallisoletana muestra un alto grado de centralidad no sólo en la red de carreteras de la región castellano-leonesa, sino dentro de la trama viaria que pone en relación a ésta con el Area metropolitana de Madrid y las regiones peninsulares del Arco Atlántico comprendidas entre la Región Norte de Portugal y el País Vasco. Es más, dentro de la perspectiva del transporte combinado y en el horizonte del acondicionamiento de la red ferroviaria de alta velocidad, Valladolid va a consolidar de manera acelerada su función como importante núcleo articulador de la red de infraestructuras de transporte del sector noroccidental de la Península, lo cual le proporciona innegables ventajas comparativas para la localización de una plataforma logística de servicios integrados que permita la organización de cadenas de transporte en ese extenso espacio suprarregional.

El alto grado de accesibilidad y centralidad de Valladolid se asienta en el trazado, capacidad, contenido funcional y previsiones de transformación infraestructural de un selectivo elenco de ejes de la red viaria, entre los que cabe destacar los siguientes: en primer lugar los grandes corredores de conexión internacional y vertebración regional - Itinerario E-80 Autovía de Castilla N620 y la Autovía del Norte N-I - Autopista A1. En segundo lugar los Grandes ejes de conexión interregional - Autovía/Autopista del Noroeste N-VI - A-6 y la Autovía de las Rías Bajas A-52, la Ruta de la Plata N-630 y la Autopista A66 y la Ruta del Duero N-122. Finalmente hay que tener presente la importancia de determinados ejes básicos de carácter complementario como son los principales accesos a Cantabria: N-611 y N-627 y algunos ejes destinados a la densificación de las conexiones intrarregionales: N-601 (tramo LeónValladolid) y CL-601, así como N-601 (tramo Valladolid-Adanero) y N-403

A fin de valorar adecuadamente el nivel de accesibilidad de Valladolid y su función dentro de la red de carreteras del espacio suprarregional del noroeste 
ibérico, es conveniente efectuar un breve apunte de los caracteres y previsiones de acondicionamiento infraestructural, así como del contenido funcional y de la capacidad de articulación territorial de un selectivo y relevante elenco de las arterias y ejes viarios relacionados. La consideración específica de cada uno de los mismos desbordaría la dimensión recomendable del presente trabajo.

\section{1.a. Los grandes corredores de conexión internacional y vertebración regional: Itinerario E-80 - Autovía de Castilla - N-620-y la Autovía del Norte-N-I-Autopista A-1}

La Autovía de Castilla-N-620 es, sin duda alguna, la arteria que deja una impronta más acusada en la vertebración de la región castellano-leonesa, si bien su contenido funcional es mucho más amplio y complejo. Constituye una infraestructura viaria de gran capacidad en el dilatado tramo comprendido entre Burgos y Salamanca. En lo que concierne al segmento que aún resta por transformar en autovía, esto es, el correspondiente a los $119 \mathrm{kms}$. que median entre Salamanca y el puesto fronterizo de Fuentes de Oñoro, se está procediendo, en el marco de las previsiones establecidas en el Plan de Infraestructuras del Estado 2000-2007, a la ejecución de las obras de nuevo trazado y desdoblamiento de calzada, con una inversión estimada en 51.404 millones de pts.

La Autovía de Castilla-N-620 configura un destacado eje integrante de las Redes Transeuropeas de Transporte, que propicia la conexión de dos importantes regiones del Arco Atlántico: la denominada "Rótula" del País Vasco (confluencia del corredor Madrid-París, del eje del Ebro y del eje de la Fachada cantábrica) con el corredor atlántico portugués Lisboa-Oporto. La conexión de ambas regiones se efectúa a través de la vía que da continuidad a la N-620 en el territorio luso, esto es, el Itinerario Principal IP-5. La Autovía de Castilla-N-620-IP-5, en definitiva, el Itinerario Europeo E-80, constituye la principal ruta de comunicación entre Portugal y el resto de la Unión Europea, perfilándose, asimismo, como el más importante segmento de enlace de la Región Norte portuguesa con Castilla y León y, hasta el momento presente, el eje en el que descansa la aún insuficiente articulación interna del espacio interregional en fase inicial de integración denominado por algunos autores Región Internacional del Duero. En virtud de todos estos factores, Valladolid ha afianzado muy notablemente su posición estratégica en la principal arteria de articulación de Portugal con el resto de la Unión Europea, al tiempo que dicha 
ciudad está adquiriendo una notable capacidad potencial para la organizar y canalizar la expansión de flujos comerciales asociados a la consolidación de la ya reseñada Región Internacional del Duero.

Paralelamente, la funcionalidad regional de la Autovía de Castilla-N-620 muestra gran trascendencia, ya que actúa como la arteria viaria que articula el corredor de mayor dinamismo de la región: el extendido entre Magaz y Tordesillas y que, estando claramente jerarquizado por Valladolid, incorpora también Venta de Baños y Palencia-Villamuriel de Cerrato. Es más, la Autovía de Castilla-N-620 propicia el enlace de este dinámico corredor con los otros dos centros urbanos regionales de mayor entidad, esto es, Burgos y Salamanca, actuando como soporte infraestructural en la articulación interna del más dinámico eje de desarrollo castellano-leonés, la denominada Diagonal castellana, mejorando el enlace del mismo con la Región Norte de Portugal.

La Autovía del Norte-N-I constituye una infraestructura viaria de gran capacidad a lo largo de toda su trayectoria, ya que presenta los caracteres técnicos propios de una autovía entre Madrid y Burgos y entre esta ciudad y Miranda de Ebro, aunque conserva las características geométricas de una carretera convencional, está funcionalmente asociada a la Autopista A-1 (Burgos-Miranda de Ebro), inaugurada en 1981 y explotada desde ese momento en régimen de peaje. En efecto, la Autopista A-1 y el desdoblamiento de la N-I desde Vitoria permiten la continuidad de un itinerario de alta capacidad en el tramo comprendido entre Burgos y Alsasua. En el marco de la trama viaria del cuadrante noroccidental de la Península Ibérica, el mencionado tramo de alta capacidad Burgos-Alsasua es el que despliega mayor proyección sobre el alto nivel de accesibilidad de Valladolid, ya que permite el enlace de la Autovía de Castilla-N-620 con la red francesa, configurando el identificado por algunos autores con Eje Irún-Aveiro.

3.1.b. Grandes ejes de conexión interregional: La Autovía del Noroeste-N-VIAutopista A-6, la Autovía de las Rías Bajas A-52 y la Ruta del Duero-N122.

La Autovía del Noroeste-N-VI constituye una infraestructura de gran capacidad en la casi totalidad de su trayectoria, pues, aunque en el tramo comprendido entre Villalba y Adanero mantiene los caracteres técnicos de una carretera convencional, está funcionalmente asociada a la Autopista A-6 (Villalba-Adanero), abierta al tráfico en 1969 y explotada en régimen de peaje 
por la empresa IBERPISTAS. El resto del itinerario de la N-VI, concretamente el comprendido entre Adanero y La Coruña-El Ferrol, está transformado en autovía. Por su parte, y desde un punto de vista funcional, la Autovía del Noroeste-N-VI también se encuentra asociada a la Autovía de las Rías Bajas A52, que a partir de su origen en Benavente, opera como un ramal de gran capacidad de la arteria radial N-VI. En efecto, la Autovía de las Rías Bajas A52 adquiere las características de trazado y desdoblamiento de calzada propios de una autovía en la totalidad de su trayectoria, enlazando directamente el Area metropolitana de Madrid, a través de Benavente, con el sur de Galicia y, en particular, con las ciudades de Orense y Vigo.

Por consiguiente, la Autovía del Noroeste-N-VI y la Autovía de las Rías Bajas A-52 proporcionan un enlace viario de alta capacidad entre Valladolid y los núcleos urbanos del eje altlántico gallego de dinamismo (sobre todo $\mathrm{La}$ Coruña, El Ferrol,Vigo y Pontevedra), al tiempo que introduce una nueva conexión con el eje de desarrollo Oporto-Lisboa y favorece el engarce con Valladolid - y, en general con la Diagonal castellana- de las áreas y centros urbanos más septentrionales de Portugal (Vila Real, Chaves, Braganza), efectando así una contribución adicional a la progresiva integración de la ya señalada Región Internacional del Duero. Asimismo, la Autovía del NoroesteN-VI y la Autopista A-6 (Villalba-Adanero) han pasado a operar como la arteria de gran capacidad para la articulación de Valladolid con el Area metropolitana de Madrid. De ahí la significación fundamental que este eje, en el conjunto de trayectoria, ha adquirido para la proyección suprarregional e, incluso, internacional de Valladolid.

El Itinerario E-82 - Ruta del Duero - N-122 muestra en la práctica totalidad de su trayectoria el carácter de carretera convencional con significativas mejoras introducidas por la aplicación del Programa de Acondicionamiento. Conviene subrayar, en este sentido, que el Plan de Infraestructuras del Estado 2000-2007 incluye una decisiva intervención estratégica en este eje, ya que prevee el acondicionamiento de la Autovía del Duero (Soria-Zamora) y de la Autovía Zamora-frontera portuguesa, que, aunque contempladas en dicho Plan como actuaciones diferenciadas, deben ser concebidas como una arteria unitaria. El acondicionamiento como autovía de la $\mathrm{N}-122$ en la casi totalidad de su trayectoria integra un conjunto de tres actuaciones, que se hacen extensivas a $352 \mathrm{kms}$. de longitud con un coste previsto de 142.000 millones de pts.

La Ruta del Duero-N-122 presenta un decisivo carácter estratégico, ya que, 
además de desplegar una notable incidencia en la articulación regional en virtud de su trazado transversal, posee un privilegiado y singular potencial como arteria de vertebración internacional. Considerados conjuntamente la N-122 y el Itinerario Principal IP-4 portugués (esto es, el Itinerario E-82 OportoValladolid-Zaragoza) pueden operar como el principal soporte potencial para la articulación del señalado espacio interregional en proceso de integración conocido bajo la denominación de Región Internacional del Duero. Asimismo, ambos ejes poseen, a través de su enlace con el vector del Ebro-Autopista A-68, el trazado idóneo para permitir la configuración de un corredor estructurante de dirección oeste-este entre Oporto y Barcelona, de notable significación a escala de la Península Ibérica.

En definitiva, el acondicionamiento y potenciación de la Ruta del Duero puede inducir repercusiones de gran alcance para Valladolid. Por un lado, permite la inserción de la ciudad en un potencial eje de desarrollo de trazado transversal, jerarquizado, junto a Barcelona y Zaragoza, por Oporto y la propia capital vallisoletana. En segundo lugar, y en el contexto del proceso de integración de la Región Internacional del Duero, acrecienta y consolida la posición estratégica de Valladolid, permitiéndole desarrollar, conjuntamente con Oporto, la función de centro bipolar en el mencionado espacio interregional integrado.

\section{1.c. Los ejes básicos de carácter complementario: el singular carácter} estratégico de los principales accesos a Cantabria (N-611 y N-627)

Sin duda alguna, el eje que muestra una clara primacía en la conexión viaria de Castilla y León con Cantabria es la N-611, que propicia el enlace directo entre el reiteradamente señalado eje de desarrollo del sector central de la región (Valladolid-Venta de Baños-Palencia) con el área central de mayor dinamismo del territorio cántabro (la embrionaria Area metropolitana de Santander, Torrelavega y los pequeños núcleos urbanos del bajo valle del Besaya), enlazando en Torrelavega con la Autovía A-67 y con la transversal Autovía del Cantábrico. En suma, la N-611 se perfila como el eje que canaliza o hacia el que confluye lo esencial de los flujos desarrollados entre el centro de la Península y el Area metropolitana de Madrid con Cantabria.

El Plan de Infraestructuras del Estado 2000-2007 establece la construcción de la Autovía Cantabria-Meseta (tramo Palencia-Torrelavega), de modo que la intervención se hace extensiva a un itinerario de $175 \mathrm{kms}$ de longitud con un 
coste previsto de 101.000 millones pts. Como es obvio, esta intervención en la N-611 afianza muy notoriamente la vinculación estratágica de Valladolid -y de todo el segmento central de la Diagonal castellana- con Santander y su área portuaria. Se actualiza y revalida, así, una relación de claro fundamento histórico, que va tener su correlato en las transformaciones que van a operarse en el eje ferroviario Venta de Baños-Santander, propiciando la configuración de un corredor multimodal con claras posibilidades del transporte combinado.

\subsection{La posición estratégica de Valladolid en la futura red ferroviaria de alta velocidad del noroeste ibérico}

Tras decenios de política ferroviaria singularizada por un cierto grado de inercia y la ausencia de decisiones estratégicas extensivas al conjunto de la red, el Plan de Infraestructuras del Estado 2000-2007, a través de su Programa de Infraestructuras Ferroviarias, introduce un drástico cambio en las políticas aplicadas en el acondicionamiento de la red, perceptible ante todo en un sesgo prioritario a favor de la potenciación de la alta velocidad ferroviaria. Pues, en efecto, el Plan de Infraestructuras del Estado, dando por concluido el periodo caracterizado por el diseño y construcción de ejes aislados de altas prestaciones, procede a la propuesta de una densa red ferroviaria de alta velocidad, inserta en la Red europea de alta velocidad. No obstante, y aunque se decanta por un diseño muy ambicioso de la red ferroviaria de altas prestaciones, el Plan de Infraestructuras del Estado -que, en el caso del Programa de Infraestructuras Ferroviarias, amplía su horizonte de desarrollo hasta 2010- muestra un notable grado de indefinición, que aconseja asumir con cautela algunas de sus propuestas.

Desbordando sensiblemente al alza las propuestas contenidas en las Orientaciones comunitarias para el desarrollo de la Red Transeuropea de Transporte, el Plan de Infraestructuras del Estado programa una densa y desarrollada red ferroviaria de alta velocidad, ordenada en su conjunto bajo la noción de Corredor Norte-Noroeste, que aparece integrado por el siguiente elenco de ejes:

El eje Madrid-Segovia-Valladolid/Medina del Campo. Se trata del gran eje troncal, a partir del cual se despliega el abanico de líneas de altas prestaciones destinadas a la articulación del noroeste español. Concebido como una línea especialmente construida para la alta velocidad, se encuentra, como es sabido, en proceso de ejecución, cuya conclusión está prevista para el año 2006, con un 
coste total estimado de 350.000 millones de pts. La construcción de la línea se encomendó en 1998 al GIF y, desde el punto de vista de sus caracteres técnicos como infraestructura de alta prestación y del desarrollo de la actividad constructiva, es posible distinguir dos tramos bien diferenciados. Por un lado, el tramo Madrid-Segovia, que constituye la definitiva materialización de la tantas veces propuesta variante de Guadarrama. De notable complejidad técnica, el elemento central de su trayectoria está constituído por el doble túnel de $27 \mathrm{kms}$. de longitud en la Sierra de Guadarrama, cuya construcción, organizada en cuatro lotes, se está desarrollando en un periodo de cinco años de duración, con un coste estimado de 180.000 millones de pts. Por otro, el segundo de los tramos aparece identificado con el trayecto Segovia-Valladolid, cuya construcción tiene un coste previsto de 100.000 millones de pts. En definitiva, esta gran arteria opera como el fundamento de la vertebración ferroviaria de altas prestaciones del noroeste peninsular, proporcionando a Valladolid la función y posición estratégica como núcleo articulador de la red ferroviaria de dicho espacio suprarregional. A partir de esta arteria troncal, se define el trazado del resto de los ejes integrantes del Corredor del Norte-Noroeste, que son los siguientes: Valladolid-Burgos-Vitoria, L. A. V. a Cantabria (Venta de BañosSantander). Palencia-León-Gijón, León-Ponferrada-Monforte de Lemos y la L. A. V. a Galicia (Medina del Campo-Lubián-Orense)

En suma, y como ha sido reseñado, el Plan de Infraestructuras del Estado, a través de la programación y desarrollo de los mencionados ejes, confiere a Valladolid la función estratégica de núcleo articulador de la red ferroviaria de alta velocidad correspondiente al noroeste peninsular, haciéndole operar, mediante la estación de mercancías, como centro redistribuidor de los tráficos de carga, con especial significación en la puesta a punto de modalidades de transporte combinado. El acondicionamiento del Puerto Seco de Santander -e, incluso, la propia ubicación del Puerto Seco de Gijón y Avilés en Venta de Baños- así lo atestiguan.

\section{UNA PLATAFORMA LOGÍSTICA EN EL CINTURÓN INDUSTRIAL DE VALLADOLID: EL PARQUE EMPRESARIAL- TECNOLÓGICO DE VEREDA DE PALOMARES -SECTOR 49-}

La puesta en valor de la posición estratégica de la ciudad de Valladolid y su entorno, en directa relación con el desarrollo de las nuevas infraestructura ferroviarias y el despliegue de nuevas estrategias locacionales por parte de la au- 
toridad portuaria del Puerto de Santander, constituye uno de los mayores retos funcionales y urbanísticos a los que se ha enfrentado la ciudad en las últimas décadas. Una adecuada articulación de todos los modos de transporte es sin duda el primer paso para afrontar los nuevos retos funcionales y territoriales, pero, si esta articulación permite a su vez la interacción y ordenación de todos los enclaves industriales y logísticos, es probable que el territorio de la ciudad pueda aproximarse al óptimo de su eficiencia económica y al óptimo de su ordenación.

Un análisis de la estructura funcional de Valladolid permite constatar que en los últimos lustros del siglo XX, -en realidad desde el Plan General de 1970- se ha venido conformando, de modo no planificado, una suerte de gran "cinturón industrial" en el que se han ido asentando todas las actividades de producción, transporte, almacenamiento y distribución de la ciudad. Como se puede apreciar en el Figura ${ }^{\circ} 3$ y en Cuadro 3, en los primeros años del siglo XXI estaban definidos en el término municipal de Valladolid y el de los mayores municipios de su entorno, al menos 14 grandes centros generadores de carga, distribuidos a lo largo de cinturón industrial que rodea la ciudad por el este y norte noroeste. Aproximadamente en posición equidistante de ambos extremos se ha decidido ubicar, dentro del término municipal de Valladolid, en el sector de Vereda de Palomares, una Plataforma Logística, aprovechando básicamente dos coyunturas irrepetibles: el trazado del by-pass ferroviario para transporte de mercancías y la ubicación del Puerto Seco de Santander. Y es que el soterramiento del ferrocarril de Alta Velocidad en su paso por la ciudad y la consiguiente separación de tránsitos -mercancías y viajeros- provocará un incremento notable de la capacidad del primero - mercancías- ya que aumentará la flexibilidad, la rapidez y la calidad de un modo de transporte que en la actualidad se encuentra sometido a las restricciones y servidumbres del tráfico de viajeros, pero que está llamado a desempeñar un papel crucial en el futuro. ${ }^{7}$

Uno de los extremos del cinturón industrial está ubicado en el Aeropuerto de Villanubla, cuya capacidad ha venido mejorando notablemente en los últimos años y en el que las obras proyectadas garantizan un rápido tránsito hacia su conversión en aeropuerto alternativo a Barajas especialmente para operaciones de tráfico de mercancías. Para reforzar el carácter funcional de este punto de ac-

${ }^{7}$ Baste considerar que en España el tráfico interno de mercancías se realiza en un $81,86 \%$ en camión, en un $11,56 \%$ en barco y en un $4,13 \%$ en ferrocarril. Parece difícil alcanzar el $30 \%$ marcado por el Estado. http://www.gotcarga.com. 
tividad, se ha proyectado la construcción de un parque de empresas aeronáuticas en terreno situado entre la nacional 601 y la futura autovía a León, que el Ayuntamiento de Valladolid ha recalificado como suelo industrial, cambiando la anterior calificación de suelo rústico. ${ }^{8}$

Cuadro 3. La actividad industrial y logistica en Valladolid

\begin{tabular}{cl}
\hline 1 & Aeropuerto de Villanubla \\
2 & Carretera de León-Gijón \\
3 & Lingotes Especiales \\
4 & Polígono industrial El Berrocal \\
5 & Carretera de Burgos, Centrolid y Mercaolid \\
6 & Michelin-Tafisa \\
7 & ACOR, Trancesa, Inespal, Industrial Tres Hermanos \\
8 & Polígonos industriales de El Esparragal y El Arenal ( Santovenia ). \\
$9-10$ & PLATAFORMA LOGÍSTICA MULTIMODAL \\
12 & Industrial Las Arenas -sec.48-, Cuesta del Tomillo e Industrial Casasola \\
13 & Polígono de San Cristóbal \\
14 & Polígono Industrial El Carrascal \\
15 & Polígono Industrial la Mora (La Cistérniga) \\
16 & Renault España, Pinar de Jalón \\
17 & Las Arroyadas (Boecillo) \\
\hline
\end{tabular}

Un segundo hito del cinturón industrial se localiza en la carretera de León; se trata un conglomerado de usos (industria, talleres, servicios) que se han venido asentando de forma irregular en origen y que está articulado ahora por el conflictivo nodo de acceso a la ronda interior desde la N-601. A los tradicionales usos vinculados a la carretera -gasolineras, hoteles, almacenes...-, se han ido añadiendo nuevos y grandes equipamientos como el Cementerio del Cerro de las Contiendas y sobre todo el Centro Comercial Equinoccio -ubicado en el término municipal de Zaratán- , para configurar un área con un alto potencial de conflictos, tanto por el desorden que presidió la génesis de este espacio - y que en cierta medida perdura todavía-, como por la extrema competencia funcional

\footnotetext{
${ }^{8}$ El artículo 26 de las directrices de Ordenación del Territorio de Valladolid y su Entorno -DOTVAENT-, en su apartado "c" señala que se debe "...habilitar el entorno meridional del aeropuerto como espacio para el desarrollo de actividades económicas, estableciendo una reserva de suelo como área de desarrollo preferente, complementaria al desarrollo del corredor Valladolid-León propuesto. DOTVAENT, Art. 36
} 
entre los términos de Valladolid y Zaratán, resuelta en una pérdida progresiva de suelo rústico y un voraz crecimiento residencial impulsado por este último. En todo caso, la elevada capacidad de conflicto está presente también en otros dos pequeños hitos, consecutivos al citado más arriba: el enclave industrial de Lingotes Especiales y el polígono industrial de promoción privada El Berrocal $-181.864 \mathrm{~m}^{2}$-, situado a $3 \mathrm{~km}$ de Valladolid, en el km. 120 de la carretera de Burgos -N. 620- que se encuentra totalmente ocupado pese a no tener adecuadamente resuelto el problema de su acceso a la Autovía de Castilla.

Un sector clave en el cinturón industrial está formado por las instalaciones de la gran plataforma alimentaria urbana de Mercaolid y el Centro Integrado de Mercancías de Valladolid -Centrolid-, ya que en cierta medida constituyen el germen de la futura gran plataforma logística multimodal de Vereda de Palomares; la presencia de ambos centros en el cinturón que hemos dado en denominar industrial -por ser esta la actividad dominante-, asegura un tránsito de mercancías muy elevado que viene a acentuar el problema de saturación que caracteriza a la mal llamada Ronda Interior; una ronda que se halla intensamente semaforizada, parcialmente colapsada, especialmente en las conexiones con las carreteras de Soria, Segovia y Madrid, que precisa del complemento de la Ronda Exterior, de trazado todavía no totalmente definido, para hacer viable la ubicación de una plataforma logística en el sector 49 -Vereda de Palomares-.

Otro núcleo de actividad de relativa importancia, localizado en el borde del término municipal de Valladolid, se ubica en el sector de Acor-Tres Hermanos. Un espacio mal ordenado, separado del Sector 49 del PGOU -Vereda de Palomares- por el Cementerio del Carmen y las vías del AVE, que estará al margen de la futura Plataforma Logística y que se completará con el sector denominado Industrial Las Arenas -sector 48 del PGOU- donde se construirá la Estación de mercancías y talleres de Renfe). En este mismo sector norte, si bien dentro ya del término municipal de Santovenia, se encuentra un polígono industrial de ocupación relativamente reciente -El Esparragal- en el que se asientan varias decenas de empresas; a pesar de su origen espontáneo y alegal en origen ha alcanzado una notable entidad, sin duda por la proximidad a Valladolid, que compartirá en breve con un nuevo polígono industrial deominado El Arenal, que dispondrá de 45 parcelas con superficies comprendidas entre los 920 y los $2612 \mathrm{~m}^{2}$.

Una vez superado el ámbito de la futura plataforma logística -denominado en el PGOU Parque Industrial Tecnológico Vereda de Palomares-se encuentran las 
mayores áreas de carga del cinturón industrial de Valladolid; tras superar el ámbito de un futuro minipolígono industrial -Cuesta del Tomillo- y un viejo enclave denominado Industrial Casasola, en el barrio de Los Pajarillos Altos, se accede al Polígono Industrial "Cerro de San Cristóbal" de Valladolid, situado entre las carreteras N-122 de Valladolid a Soria, CL-601 de Valladolid a Segovia. Es una de las mayores superficies de uso industrial de la Comunidad Autónoma de Castilla y León -cerca de 240 hectáreas-, en la que se ubican más de 900 empresas que ocupan a cerca de 23.000 trabajadores. Presenta problemas de accesibilidad, parcialmente resueltos tras la puesta en servicio de la variante de la Cistérniga, que se agravan no obstante por la falta de un plan logístico que ordene todo el sector, así como por la tipología de empresas -de pequeño tamaño- y el sector de actividad al que pertenecen -servicios a las empresas, servicios personales, talleres, comercio al por mayor, almacenes, transporte... - que se caracterizan por su elevada movilidad.

Un polígono industrial en fase de progresiva ocupación es el de la Mora, en el municipio de La Cistérniga. Está ocupado por pequeñas industrias y notable actividad de almacenamiento, pero con accesos inadecuados. Si continúa creciendo la actividad de almacenamiento en el polígono de la Mora los problemas de tráfico pueden ser muy agudos en este sector, especialmente cuando se construya la variante planteada por el Ministerio de Fomento para el desvío del ferrocarril, ya que bordea el término municipal de Valladolid, atraviesa la C-511 y la $\mathrm{N}-122$ y separa el municipio de la Cistérniga y su polígono industrial. Este horizonte hace todavía más urgente el planteamiento de una zona de actividades logísticas de entidad que evite la dispersión y el tráfico interior en los municipios del entorno.

Tres áreas más vienen a afianzar la vocación industrial del sureste de Valladolid: se trata de la factoría de Renault-España, el Polígono del Carrascal, con 86 has., previsto por S.E.P.E.S. como ampliación del polígono industrial Cerro de San Cristóbal y los sectores 44 -Industrial Jalón- colindante con la parte posterior de Renault, y el sector 38 -Pinar de Jalón- de uso mixto $80 \%$ residencial y $20 \%$ industrial. La proximidad de estos tres enclaves industriales y su ubicación entre la ronda Exterior Sur y el by-pass ferroviario afianza asimismo la necesidad de organizar los tránsitos, vinculándolos a la futura estación de mercancías y plataforma logística multimodal de Vereda de Palomares. ${ }^{9}$

\footnotetext{
${ }^{9}$ La ampliación del Polígono Industrial "Cerro de San Cristóbal”, promovida por
} 
Finalmente, el cinturón industrial se completa, por el Sur, con el polígono Industrial Las Arroyadas, en Boecillo, donde se ubica el Parque Tecnológico de Castilla y León; fue inaugurado en Abril de 1992 y tiene, tras la incorporación de su tercer recinto, una superficie de 119 hectáreas. En Diciembre de 2002 estaban radicadas en el Parque cerca de 80 empresas y tres centros tecnológicos de la Universidad de Valladolid. Su localización y próxima mejora de accesos, tras la construcción de la Autovía Laguna de Duero-Boecillo, consolidará el polo sur del cinturón industrial de Valladolid.

Como se puede apreciar en el Gráfico no 3 , la plataforma logística se situará en una posición intermedia en el cinturón industrial, en el punto de mayor intermodalidad -conexión carretera y ferrocarril-, de forma que puede proporcionar servicio logístico tanto a la mercancía captada por el aeropuerto de Villanubla, a la que proceda de la actividad generada por la ciudad, a la que provenga por ferrocarril o carretera del puerto de Santander con destino a su Puerto Seco en Valladolid y la que se capte desde el sur, tanto por carretera como por ferrocarril, aprovechando las necesidades de distribución y conexión de la Comunidad de Madrid con el norte y noroeste peninsular. De este modo quedaría perfectamente integrada la actividad económica de Valladolid con la de los municipios ubicados en los extremos noroeste y sur del cinturón, Villanubla y Boecillo, y con la de los municipios situados en posición intermedia en el mismo: Santovenia y la Cistérniga al Norte y Este, respectivamente.

Para que estos focos de actividad sean viables, se debería crear una suerte de "corredor metropolitano de carga" acondicionado para la circulación de vehículos de transporte de carga, bien señalizado e identificado, de forma que toda la generación de valor añadido se pueda concentrar en un único sector: la zona de actividades logísticas de Vereda de Plomares; un sector que en una primera aproximación cumple dos de las cuatro condiciones básicas que precisa una zona estas características, a saber: tiene una localización estratégica en la infraestructura viaria (está ubicado entre la ronda interior y exterior), y ha sido promocionado a escala local y regional al ubicarse la estación de mercancías y el

SEPES se ha empezado a resolver tras la autorización por el Consejo de Ministros de 25, X, 2002 de la licitación de las obras de urbanización de una superficie de 86 hectáreas de suelo, con un presupuesto de 13,76 M€ y un plazo de ejecución previsto de 18 meses. Esta obra aportará al tejido industrial de Valladolid $454.000 \mathrm{~m}^{2}$ de parcelas industriales y terciarias y $403.000 \mathrm{~m}^{2}$ de espacios públicos -zonas verdes, dotaciones públicas y viario- que serán cedidos al Ayuntamiento 
Puerto Seco de Santander, pero que en cambio puede estar muy alejado del óptimo locacional al carecer de algunos atributos esenciales en toda plataforma logística.

Existe acuerdo entre los técnicos y operadores del sector de la logística en considerar que una plataforma logística es atractiva sólo si dispone de suelo abundante para poder realizar con holgura todas las operaciones de carga y descarga vinculadas al modo dominante que será el ferroviario y que este suelo tenga posibilidades de ampliación, tanto para las actividades de transporte y logística propiamente dichas como para las actividades y servicios complementarios $^{10} ; \mathrm{y}$ también si dispone de espacios libres que aumenten el atractivo paisajístico y medioambiental del entorno. Debe ofrecer también suelo urbanizado a precio competitivo con relación a otras plataformas y a otras áreas industriales de la ciudad y debe disponer de una alta conectividad terrestre, por medio de las redes generales de autopistas, autovías y ferrocarril. Se considera también muy adecuado un emplazamiento que ponga en valor una zona de fachada para rentabilizar el "efecto escaparate" para todos los tránsitos, especialmente para el transporte por carretera. $\mathrm{Y}$ a mayor abundamiento debe dotarse de una organización y gestión eficiente que integre toda la oferta logística local-regional, con el objeto de hacer aumentar las economías de escala de la propia plataforma y que facilite la movilidad de las empresas y que pueda responde a la demanda de diversos tamaños y requerimientos técnicos de parcelas.

Utilizando una matriz DAFO (debilidades, amenazas, fortalezas y oportunidades) podemos realizar una primera valoración de la capacidad del término municipal de Valladolid para la implantación de las actividades logísticas en la que destaca la idoneidad de la situación, el valor de decisiones estratégicas como la de ubicar el Puerto Seco de Santander por una parte y las incertidumbres relacionadas con el mercado de suelo industrial que resta competitividad a la ciudad y, obviamente con las insuficiencias del emplazamiento finalmente elegido y acondicionado: Vereda de Palomares.

Plataforma Logística Multimodal de Valladolid. Fortalezas, debilidades,

${ }^{10}$ A modo de ilustración, en la Plataforma Logística de Zaragoza, la zona ferroviaria (zona de clasificación de mercancías -30 vías paralelas con aproximadamente un kilómetro de longitud- estación y talleres de reparación) ocupa 76 hectáreas a las que hay unir 84 más que acogerán la Zona de Intercambio de Mercancías (CIM) que en estos momentos está operativo en Utebo, cerca de Pikolín. 
oportunidades y amenazas

Fortalezas

Debilidades

Posición geográfica estratégica.

Adecuado nivel de infraestructuras logísticas: aeropuerto, Centro Integrado de Mercancías, nueva estación de mercancías, Línea de Alta Velocidad.

Alta capacidad para generar tráfico de mercancías. Denso tejido industrial.

Creciente toma de conciencia de la relación entre competitividad y logística.

Próxima construcción del Puerto Seco de Santander.

Creciente presencia de operadores logísticos en Valladolid: Capital Regional.

Proximidad a la mayor infraestructura logística de España: Madrid.
Atomización del sector de operadores logísticos.

Escasa implicación institucional en la promoción- planificación de un gran centro logístico regional de carácter multimodal.

Escasa eficacia de las medidas orientadas a la reducción del precio del suelo industrial.

Espacio de crecimiento limitado por la Ronda interior y exterior, la nueva línea del AVE y un gran sistema general: el cementerio del Carmen

Diseconomías derivadas de la proximidad al tejido urbano y de la congestión de la Ronda Interior -corredor de carga-

Oportunidades

Amenazas

Potenciación de la situación estratégica de Valladolid.

Elevado volumen de obra pública de la llamada "operación ferroviaria"

Adecuada estructura intermodal.

Colaboración entre los diferentes integrantes de la cadena de suministros.

Incorporación de nuevas tecnologías para garantizar la calidad de servicio.

Oportunidades para los operadores logísticos (especialización ...).
Saturación de infraestructuras y congestión en el Norte

Excesivo consumo de suelo en el término municipal de Valladolid.

Precio del suelo elevado al haberse recalificado antes del inicio de las expropiaciones.

Falta de definición institucional sobre la estructura logística regional

Competencia con los puertos Secos, C.I.T. y plataformas del entorno regional: Benavente, Ventasur -Venta de Baños- , Burgos... 


\section{CONCLUSIONES.}

Frente a las indudables ventajas que ofrecería el emplazamiento de una gran infraestructura logística fuera de los límites de una ciudad -en nuestro caso del término municipal de la ciudad de Valladolid-, es obvio que cualquier alternativa que se inserte o se adose a un tejido urbano puede ser una considerable fuente de problemas futuros ya que todas las diseconomías que esta actividad genera -relacionadas con la intensidad de tráfico y la necesidad de consumir un elevado volumen de suelo para una rentabilidad o aprovechamiento muy bajo- quedarán inscritas dentro del perímetro urbano.

A mayor abundamiento, al haberse optado en Valladolid por una localización intraurbana se tendrá que asumir una enorme paradoja, como es que la ciudad, que no ha sabido retener en la última década algunos usos -especialmente residenciales- ante el abuso de los precios del suelo y vivienda y la feroz competencia de los municipios de su entono, se disponga, en cambio, a acaparar concentrar- nuevos usos relacionados con la logística, que son muy exigentes en suelo e infraestructuras de transporte, que agotan prácticamente todo el suelo por el norte a costa de una irreparable pérdida de suelo rústico de especial protección y que condicionarán todo el crecimiento futuro de la ciudad, incluso el residencial. De materializarse este proyecto de área logística en el norte, la imagen final de la ciudad será una suma de paradojas y contradicciones: estará formada básicamente por una ciudad "central" compacta, ceñida por un extenso cinturón de actividad -industrial, logística etc..., con no menos de 15 enclaves industriales y más de 500 has de uso logístico-transporte-almacén; esta ciudad central estará bordeada por pequeños términos municipales de carácter fundamentalmente residencial- casi todos los que forman el "entorno" de Valladolid delimitado en las Directrices de Ordenación del territorio de Valladolid y su Entorno, aprobadas por decreto 206/2001, de 2 de Agosto. ${ }^{11}$

En definitiva, una infraestructura de la entidad de una Plataforma Logística, esencial para la provincia de Valladolid, no tiene necesariamente que ubicarse

${ }^{11}$ Forman el ámbito de las DOTVAENT los municipios de: Cigales, Santovenia de Pisuerga, Cabezón de Pisuerga, Fuensaldaña y Mucientes, por el valle del Pisuerga hacia el norte. Renedo de Esgueva, Castronuevo de Esgueva, La Cistérniga y Tudela de Duero hacia el este, por los valles del Duero y la Esgueva. Laguna de Duero, Boecillo, Aldeamayor de San Martín, Viana de Cega, La Pedraja de Portillo, Valdestillas y Villanueva de Duero, hacia el sur (Tierra de Pinares). Y Simancas, Arroyo de la Encomienda, Geria, Ciguñuela, Zaratán y Villanubla hacia el oeste, al otro lado del Pisuerga. 
en el término municipal de su capital. No es concebible que se hayan aprobado unas directrices de ordenación subregional-DOTVAENT- para seguir concentrando todo el crecimiento en la ciudad de Valladolid y convertir en reserva paisajística-residencial a su entorno. La actividad logística no sólo es tributaria del dinamismo de la ciudad de Valladolid; lo es también y sobre todo, de las infraestructuras de transporte-Autovía de Castilla, Ferrocarril- cuyos puntos de ruptura de carga no deben estar condicionados por la necesidad de regenerar eriales industriales -Nicas, Endasa-, ubicar una nueva estación de mercancías o justificar una reconversión de suelo rústico a urbanizable, sino por criterios de eficiencia, oportunidad y futuro. ${ }^{12}$

\section{BIBLIOGRAFÍA.}

ANAYA TEJERO J. J. (2000): Logística integral : la gestión operativa de la empresa. Madrid Esic

BAVOUX, J.J. Y CHARRIER, J.B. (1994): Transports et structuration de l'espace dans l'Union Européenne. Paris, Masson. 222 págs.

BRUNET, R. (1993): «L'enjeu du transport». L'Espace géographique $\mathrm{N}^{\circ} 22$. pp. 219 a 232.

CASANOVAS, A. y CUATRECASAS, Ll. (2001): Logística empresarial. Barcelona. Gestión 2000.

DotvaenT. (1998): Directrices de Ordenación Territorial de Valladolid y su entorno. Consejería de Medio Ambiente y Ordenación del Territorio. Junta de Castilla y León.

FARRÁN J. [et al.] (1996 ): Distribución y logística Pamplona. Eunsa, JIMENEZ DE CISNEROS CID, F.J. (1997): «Transporte combinado y actividades logísticas: el marco jurídico de los servicios ferroportuarios». Ciudad y Territorio. Estudios Territoriales XXIX (111). pp. 115 a 125.

MINISTERIO DE FOMENTO. SECRETARÍA DE ESTADO DE INFRAESTRUCTURAS Y

${ }^{12}$ La conversión en urbanizable de suelo rústico de especial protección, se inicia con el expediente 02/2002 de 16 de Agosto, relativo a la modificación puntual del PGOU de Valladolid entre la Ronda Interior y exterior al Norte del Esgueva. Mediante esta operación se han descatalogado nada menos que 470 has de suelo no urbanizable protegido nivel 2, (N2) definido como "...áreas de alto valor agrícola actual o de las que potencialmente se pueda obtener una elevada productividad -art. 283-." La mayor parte de este suelo corresponde a grandes fincas agrícolas de regadío: Palomares, Las Arenas, Simancas Ganadera y Entre Esguevas. 
TRANSPORTES (1999): Los centros de transportes de mercancías en España: conceptualización, elementos a considerar en relación a su ubicación y contribución al potenciamiento de la intermodalidad.

PAU I COS, J., NAVASCUÉS Y GASCA, R., YUBERo ESTEBAN, M. (1998): Manual de logística integral. Madrid. Díaz de Santos,

PRADO PRADO J.C., GARCÍA LORENZO, A., GARCÍA ARCA , J. (2000): Dirección de logística y producción. Vigo. Universidad de Vigo.

PRIDA ROMERO, B. (1999): Logística de aprovisionamiento.El cambio en las relaciones proveedor-cliente, un nuevo desafio para la empresa del siglo XXI. Madrid, MacGraw-Hill.

SAVY, M.(1993): Logistique et territoire. Le nouvel espace des transports. Montpellier, Reclus. Págs. 140.

\section{WEB}

http://www.pgouvalladolid.com http://www.gotcarga.com http://www.telecotrans.es http://www.euskadi.net http://www.puntolog.com http://www.adl-logistica.org http://www.estrategia.net http://www.dbk.es http://www.fomenweb.com http://www.guiame.net http://magno.uab.es http://www.cel-logistica.org http://www.puertosantander.es http://www.ctc-coslada.com http://www.plazadosmil.com http://www.fcavn.es http://www.zal.es http://www.investinmadrid.com http://www.mfom.es http://www.eurociudad.org http://www.puntolog.com http://www.jcyl.es 


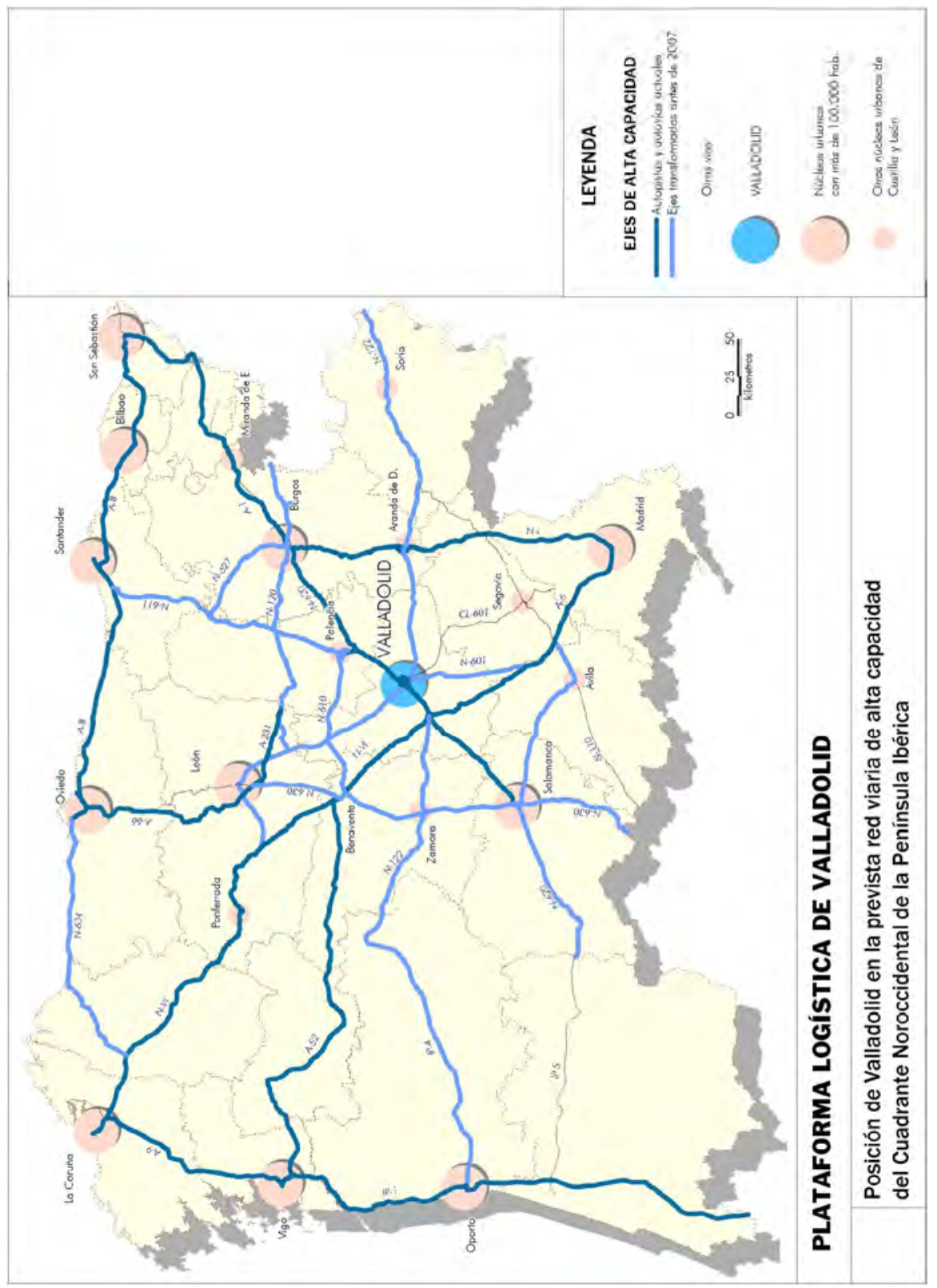

Figura 1

Polígonos. Revista de Geografia, 11-12 (2001-2002); pp.11-44. 


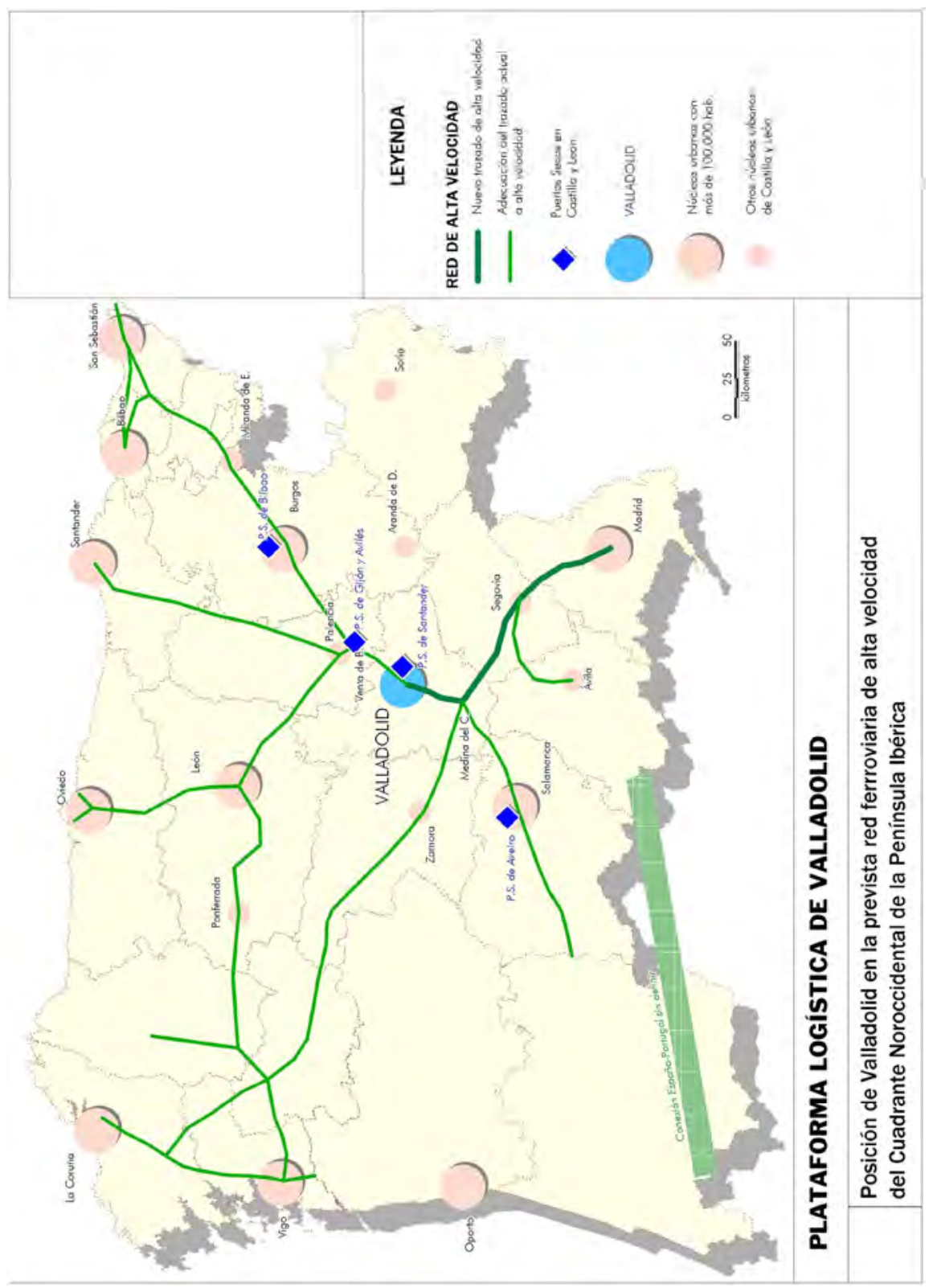

Figura 2

Polígonos. Revista de Geografia, 11-12 (2001-2002); pp. 11-44. 


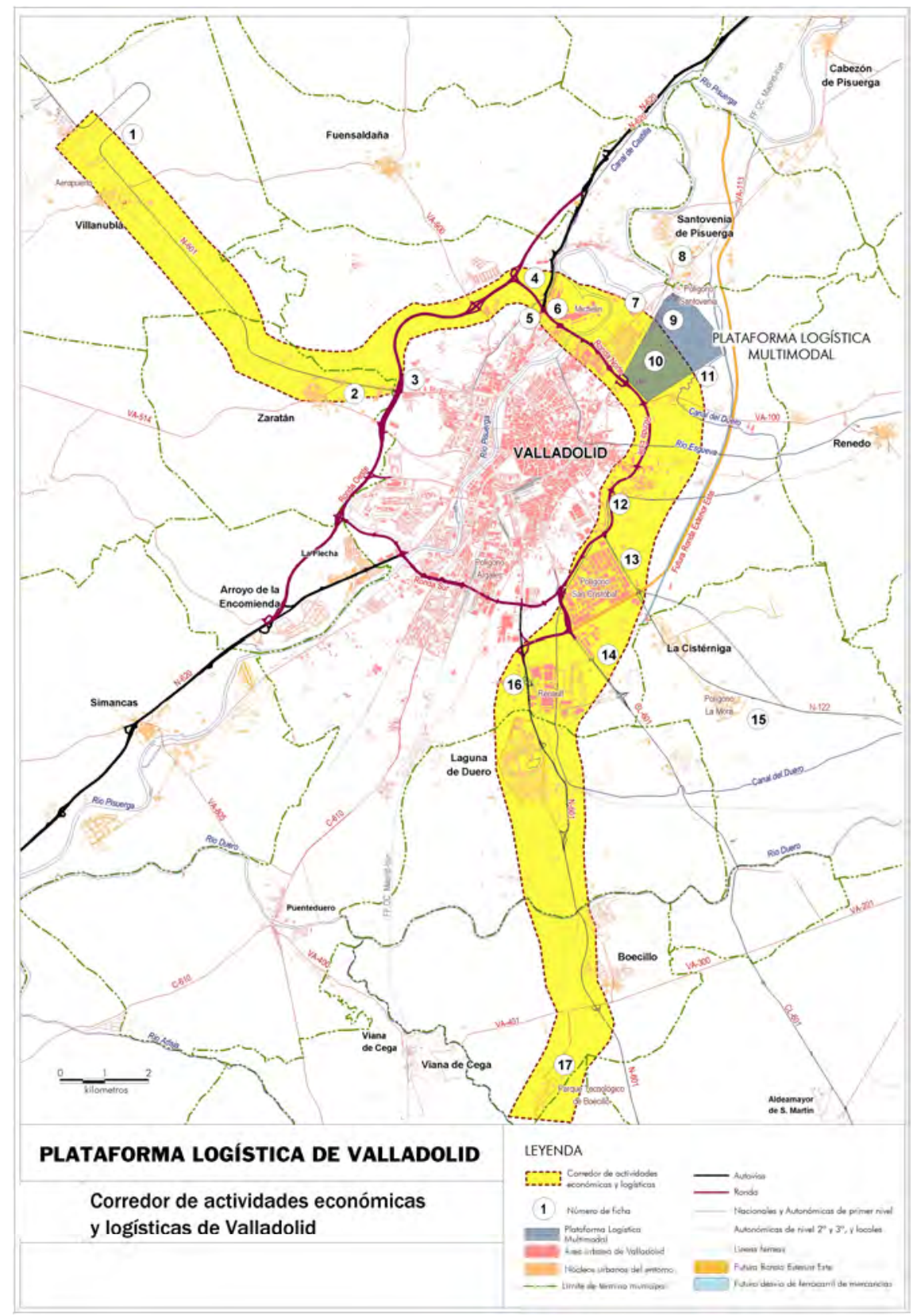

Figura 3

Polígonos. Revista de Geografia, 11-12 (2001-2002); pp.11-44. 


\section{RESUMEN.}

El desarrollo de la red ferroviaria de alta velocidad en la primera década del siglo XXI proporcionará a Valladolid innegables ventajas comparativas para instalación de una plataforma logística multimodal, contemplada en el PGOU-2003, concebida para poder competir con las grandes infraestructuras logísticas de otras regiones españolas y que pueda contribuir a solucionar también, los graves problemas de ordenación de la industria y transporte de la ciudad

Palabras clave: Logística, plataforma logística multimodal, ordenación del territorio.

\section{ABSTRACT}

The development during the first decade of the Twentieth century of the railway network of high speed, according to the PGOU-2003, will provide to Valladolid many advantages for the location of a multimodal logistic platform that can compete with the logistic infrastructure of other Spanish regions and also this platform can contribute to solve the serious problems of arrangement of the industry and transport of the city.

Key words: Logistic, multimodal logistic platform.

\section{RÉSUMÉ}

Le développment du réseau ferroviaire à grande vitesse dans la première dècade du XXI ème siècle apportera à Valladolid de grands avantages comparatifs pour l' installation d'une plate-forme logistique incluse dans le PGOU-2003, et conçue pour faire concurrence aux grandes infraestructures logistiques d'autres régions espagnoles et afin de résoudre également les lourds problèmes d'aménagement de l'industrie et du transport de la villa de Valladolid.

Mots clé: Logistique, plate-forme logistique multimodale. 